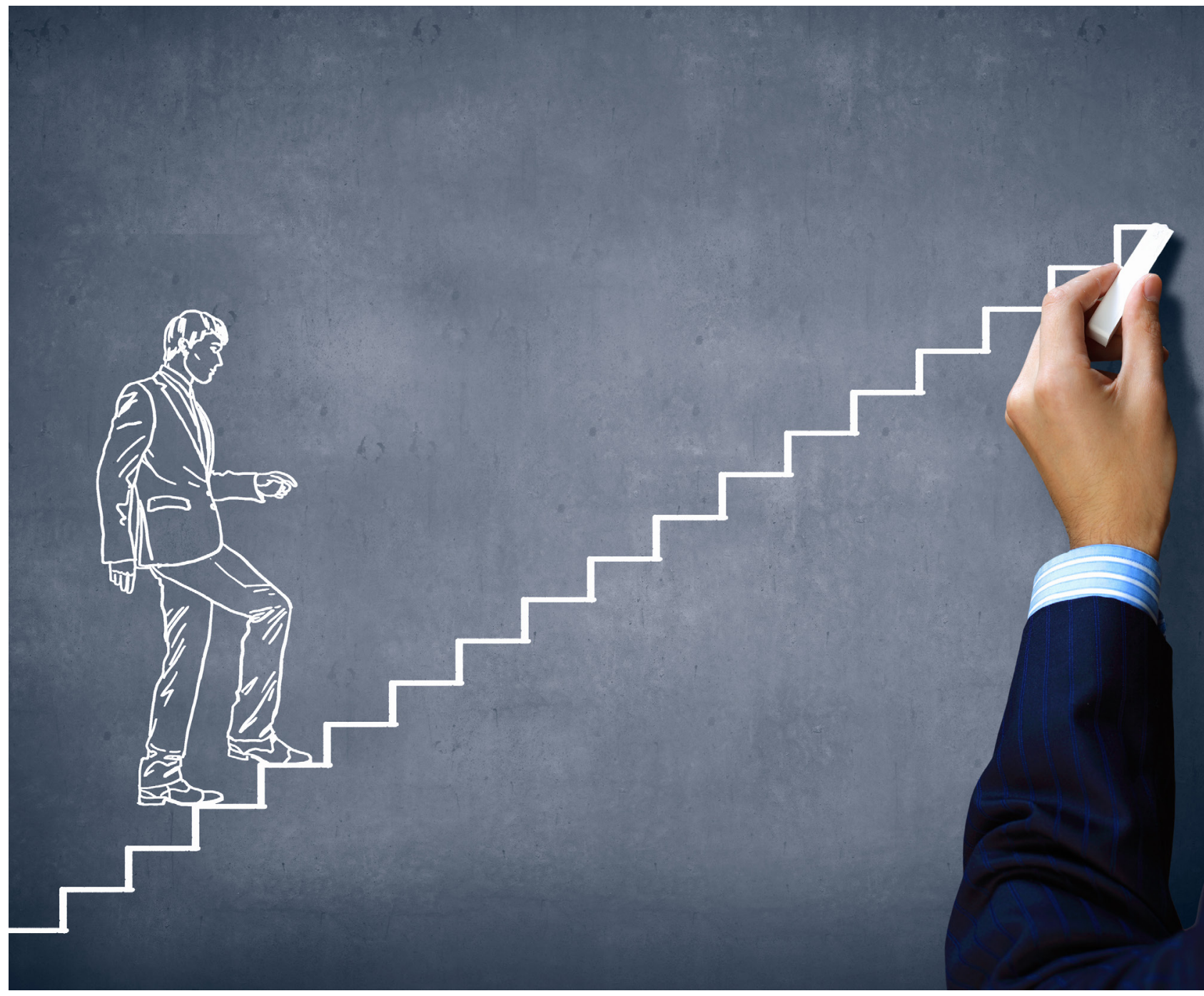

\title{
CONHECIMENTO E IMPACTO EM GESTÃO
}

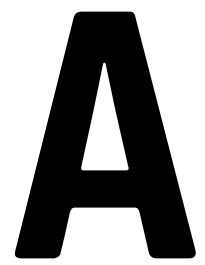

partir de 2017, a $G V$-executivo passa a ter seis edições anuais e tem seu conteúdo totalmente reformulado. Queremos conversar com alunos, ex-alunos, empresários, executivos, gestores públicos e empreendedores e, por meio da disseminação de pesquisas inéditas, impactar e transformar as organizações e a sociedade brasileira. Vamos discutir ideias e tendências inovadoras, bem como compartilhar experiências de profissionais que estão mudando o cenário social e organizacional de nosso país. A nova diretriz editorial da $G V$-executivo propõe um conteúdo transformador e de qualidade em meio à sobrecarga de informações a que estamos expostos todos os dias. 
A partir de inúmeras pesquisas aplicadas conduzidas em 14 centros de estudos da FGV EAESP, da experiência única do Mestrado Profissional em Gestão para a Competitividade, com linhas de pesquisa em Varejo, Finanças e Controladoria, Tecnologia de Informação, Saúde, Sustentabilidade e Operações e Logística, e do Mestrado Profissional em Gestão e Políticas Públicas, divulgaremos o conhecimento de professores, pesquisadores e gestores de alta qualificação de empresas públicas e privadas, com um relevante diferencial: disseminar o conhecimento aplicado, produzido por aqueles que têm contato direto com a realidade do mercado brasileiro, com organizações públicas e suas especificidades locais e com novos negócios desenvolvidos no cenário atual.

Também vale ressaltar que a rede internacional da FGV EAESP nos permite contar com pesquisas aplicadas de estudiosos estrangeiros em parceria com os professores da Escola. Sabemos que a divulgação de pesquisas de impacto, as quais têm a capacidade de redirecionar políticas empresariais e públicas, fazem parte da atuação da FGV, reconhecida nacional e internacionalmente como Think Tank, promovendo, de fato, mudanças organizacionais e sociais.

Além disso, publicaremos artigos que estimulam o senso crítico e a reflexão do leitor, para auxiliá-lo no planejamento e na diferenciação de suas atividades práticas, e veicularemos entrevistas com altas lideranças, de modo a compartilhar suas experiências, estratégias e aprendizados.

Assim, esta edição traz um Caderno Especial sobre varejo, apresentando artigos provocantes, escritos por quem pesquisa e faz esse segmento. O coordenador do Centro de Excelência em Varejo (GVcev) da FGV EAESP, professor Maurício Morgado, aponta os três grandes desafios para o varejo do futuro e explica que será preciso lidar com um processo de compra cada vez menos previsível, administrar um volume gigante de informações e encontrar novas funções para as lojas físicas. No artigo Adotar ou não as novas tecnologias no varejo?, Henrique de Campos Junior mostra os benefícios de inovações como realidade aumentada, sensores, telas táteis interativas e as melhores formas de implantá-las. Benjamin Rosenthal discute que o desafio do marketing na era digital é gerenciar centenas de ações na internet para atingir um consumidor que tem cada vez mais poder na relação de compra. Tânia Veludo-de-Oliveira, Edgard Barki e Felipe Zambaldi abordam um tema muito inovador: microdoações. Ao possibilitar que o cliente destine o troco de suas compras para causas socioambientais, o varejo pode ser um grande aliado na disseminação da cultura de doação no Brasil. Leandro Guissoni destaca a importância da gestão omnichannel e afirma que os varejistas precisam desenvolver a capacidade de analisar as informações do mundo online e offline de forma integrada para ganhar vantagem competitiva. Juracy Parente e Marina Henriques Viotto debatem que condutas mais éticas e transparentes com clientes, relacionamento com funcionários de mais confiança e objetivos além dos resultados financeiros são tendências que já fazem a diferença entre os varejistas de sucesso. Delane Botelho e Ramona de Luca expõem como o varejo investe no marketing olfativo para criar uma experiência única e estabelecer maior conexão com o consumidor nas lojas físicas. Finalmente, o artigo de Marcelo Silva, A importância da sucessão nas empresas de varejo brasileiras, revela que, para ter crescimento sustentável, a empresa precisa planejar bem a passagem do negócio para as próximas gerações, juntamente com seu processo de profissionalização.

Ainda nesse sentido, a $G V$-executivo traz uma entrevista exclusiva com Abilio Diniz, conhecido por sua trajetória de sucesso no varejo. O empresário fala sobre sua reinvenção nos últimos anos, como superar momentos de crise e liderança.

Completam a edição as colunas Fora da Caixa (Flexibilização dos padrões morais), de Samy Dana; Economia (Incertezas da estabilização), de Paulo Sandroni; Sociedade e gestão (De il principe a il esecutivo: Maquiavel no século XXI), de Fernando Nogueira; e Gestão (Político ou gestor? Provocações desse falso dilema), de Marco Antonio Teixeira.

Além da publicação de artigos de membros da rede da FGV EAESP, gostaríamos de contar com a colaboração de executivos e professores de todas as regiões do Brasil, para que a $G V$-executivo possa disseminar e agregar conhecimento com alto impacto em gestão.

Por fim, agradecemos à equipe RAE-publicações, especialmente a Aline Lilian dos Santos, que abraçou o novo projeto rapidamente e organizou a produção da revista, com o valioso apoio da nova editora adjunta, Adriana Wilner, jornalista com experiência no mercado editorial e no universo acadêmico de Administração. Agradecemos também aos patrocinadores desta edição: PricewaterhouseCoopers (PwC), Centro de Excelência em Varejo (GVcev) e Mestrado Profissional em Gestão para a Competitividade da FGV EAESP.

Esperamos que apreciem as novas diretrizes da $G V$-executivo, bem como sua periodicidade bimestral, que nos deixa ainda mais próximos de nossos leitores.

Boa leitura!

Maria José Tonelli - Editora chefe 